\title{
An interesting ligand for the preparation of luminescent plastics: the picrate ion
}

V. de Zea Bermudez

Secção de Química, Universidade de Trás-os-Montes e Alto Douro, Apartado 202, Quinta de Prados, 5001 Vila Real Codex, Portugal

L.D. Carlos

Departamento de Física, Universidade de Aveiro, 3800 Aveiro, Portugal

M.M. Silva and M.J. Smith

Departamento de Química, Universidade do Minho, 4719 Braga, Portugal

\begin{abstract}
Electrolytes formed with poly(oxyethylene), POE, and europium picrate $\left[\mathrm{Eu}(\text { pic })_{2}\left(\mathrm{OH}_{2}\right)_{6}\right]$ pic. $6 \mathrm{H}_{2} \mathrm{O}$ (where pic denotes the picrate anion) or simply $\mathrm{Eu}(\mathrm{pic})_{3} \mathrm{xH}_{2} \mathrm{O}$, have been represented by $\mathrm{POEnEu}(\text { pic) })_{3} \mathrm{xH}_{2} \mathrm{O}$ (where $\mathrm{n}$ represents the molar ratio of $\left(\mathrm{OCH}_{2} \mathrm{CH}_{2}\right)$ units per $\mathrm{Eu}^{3+}$ ion). Materials with $\mathrm{n}$ ranging from 133 to 11 have been examined. A tentative attribution of the absorption bands of the mid-infrared spectra is presented. The spectral changes detected in the mid-infrared region and the modifications in the XRD patterns at increasing salt content show that $\mathrm{PEO}_{\mathrm{n}} \mathrm{Eu}(\text { pic })_{3} \mathrm{xH}_{2} \mathrm{O}$ exerts an effective plasticizing role which leads to the complete supression of crystallinity at $\mathrm{n}=11$. The emission spectra of the complexes and their signature in the $v \mathrm{C}-\mathrm{O}$ spectral region provide conclusive evidence that the $\mathrm{Eu}^{3+}$ ions are coordinated to the oxygen atoms of the polyether chains over the whole range of compositions studied. The photoluminescence spectra of the $\mathrm{PEO}_{\mathrm{n}} \mathrm{Eu}(\mathrm{pic})_{3} \mathrm{xH}_{2} \mathrm{O}$ electrolytes indicate that the $\mathrm{Eu}^{3+} /$ ether oxygen complexation occurs with concomittant partial substitution of the water molecules from the cation coordination shell. The luminescence data obtained confirm that the latter aspect is quite advantageous from the standpoint of optical properties.
\end{abstract}

\section{Introduction}

Solid solutions of polymers with salts have been a topic of intense study during the last two decades due to their wide range of electrochemical applications, in particular, as electrolytes in all-solid-state batteries, smart windos and sensors [1-3]. In these systems the salt is partially 
dissociated in the polymer matrix which plays the role of solvent and this process leads to electrolyte behaviour.

The polymer which has been most extensively investigated as a host matrix is poly(oxyethylene), POE. This hard polybasic molecule is an open macromolecular structure composed of $\mathrm{OCH}_{2} \mathrm{CH}_{2}$ repeat units which act as polydentate ligands with a remarkable ability to coordinate cations through the ether oxygen atoms. In this sense POE may be considered to be the polymer analogue of crown ethers. It is therefore not surprising that the development of polymer electrolytes has closely accompanied that of host-guest chemistry.

Although alkali metal [4], alkaline earth and several other divalent metal salts [5] have received the most attention, in recent years lanthanide metal ion-containing polyethers have also been the subject of intense research because of their potential use as plastic lasing or phosphor materials. The latter systems elegantly combine the ready processability of polymer with the unique intrinsic characteristics of lanthanide ions, in particular, long lifetimes of the emitting states and narrow emission bands in the visible region.

\section{Conclusion}

In this paper several members of a family of interesting polymer electrolytes prepared by dissolving $\left[\mathrm{Eu}(\mathrm{pic})_{2}\left(\mathrm{OH}_{2}\right)_{6}\right]$ pic. $6 \mathrm{H}_{2} \mathrm{O}$ in POE have been characterized in detail by infrared and photoluminescent spectroscopies. Their morphology has been analyzed by X-ray diffraction.

Over the whole range of salt concentrations investigated the macromolecular host structure performs two important functions, providing not only the solvating interaction with the $\mathrm{Eu}^{3+}$ ions which maintains the europium picrate complex in solution, but also serving as a means by which the luminescent species is encapsulated, isolating it from the external environment. Although the two coordinated picrate ligands remain unaffected by the $\mathrm{Eu}^{3+/}$ ether oxygen complexation, a number of water molecules are lost from the first coordination shell of the lanthanide cation. The result in terms of optical activity is a significant reduction of the luminescence quenching. This quite unusual and beneficial aspect transforms the hydrated europium picrate into a very attractive salt for the preparation of polymeric materials with appropriate optical properties. A further advantage of $\mathrm{Eu}(\mathrm{pic})_{3} \mathrm{xH}_{2} \mathrm{O}$ derives from its remarkable plasticizing ability. Due to the bulkiness of the picrate ligands, the formation of totally amorphous electrolytes is made possible at a high salt content. 


\section{References}

1. D. E. Fenton, J. M. Parker and P. V. Wright, Polymer 14 (1973) 589.

2. M. Armand, J. M. Chabagno and M. Duclot, in Fast Ion Transport in Solids, Ed. P. Vashishta, J. N. Mundy and G. K. Shenoy (North Holland, New York, 1979).

3. J. R. MacCallum and C. A. Vincent, Polymer Electrolyte Reviews Elsevier, London 1987.

4. M. B. Armand, M. J. Duclot and P. Rigaud, Solid State Ionics 3/4 (1981) 429.

5. A. Patrick, M. Glasse and R. G. Linford, Solid State Ionics 18/19 (1986) 1063. 